\title{
U.S.-CHINA RELATIONS IN THE NORTHEAST ASIAN SECURITY CONTEXT
}

\section{By Eric A. McVadon. Rear Admiral, U.S. Navy (Retired)}

June -1999

\section{Introduction}

A good way to start a discussion of the relations of the U.S., China, and Northeast Asian Security is to remind ourselves of the importance of U.S. alliances in NEA. This is a factor that many analysts consider instrumental in bringing about the peace and stability that has allowed so much Asian economic and political progress in the latter half of this century. These U.S. alliances with Japan and the ROK are the bedrock of East Asian security from the American point of view. However, change will come on the Korean Peninsula, at some time and in some form that is hard to predict. At that time, there will be serious questions about the need and wisdom of keeping American forces in significant numbers in NEA. There will be at least adjustments in numbers, missions, and capabilities. My concern is that we will act too quickly, change things we wish we had not changed, and live to regret our hasty actions.

So much for the American view. Let me now turn to the Chinese viewpoint. The Beijing-Moscow "strategic partnership" is proclaimed by Chinese leaders as a model of security relations: Alliances are considered "Cold War thinking, inevitably implying alliance adversaries, there is to be no hegemony or power politics, and there should be a new political and economic world order based on a multicolor rather than univocal world. These may be rather grand-sounding words, but they are China's dream, one that is, at least at first look, incompatible with the aspirations of the U.S. to retain its bilateral alliances as the most prominent aspect of security in the region.

China is no longer sure that American presence in Japan serves China's interests. Yes, the U.S. military presence curbs Japanese militarism (a great fear in China), but now there are the revised Defense Guidelines for the Japan-U.S. security arrangements and the prospect of TMD for Japan. Beijing considers these as factors likely to encourage the resurgence of Japanese militarism. Japan, China argues, will forget the word self in the term Japanese Self-Defense Force and consider that the entire Asia-Pacific region is encompassed in Japan's security area. TMD joint research, according to Beijing, will make technology available to Japan to facilitate development of ballistic missiles that can be tipped with nuclear warheads. Japan, the Chinese assert, could develop nuclear 
weapons in a very short time. To most American specialists on Japanese Security, these are not well-founded fears. Too many, they are at least irrational concerns if not absurd conclusions, but they are very real to the Chinese. A Future Security Architecture

With these factors in mind, it is appropriate now to see how we might move toward a new or evolving security framework for Northeast Asia. It must be said at the outset that, to my knowledge, no one is seriously proposing anything resembling one of the two prominent extremes of security architecture, NATO and the ARF, as a likely model for the countries of Northeast Asia - a region of countries and relationships that resemble neither Europe nor Southeast Asia. It should also be said that there is essentially nothing now that suggests a new or modified framework need be formal, or even that it be defined or documented in any sort of rigorous way.

To the contrary, those who are thinking about the transition are intentionally and consistently employing abstract (even vague) terms such as security architecture or security framework. There may be several good reasons for doing this: (1) it is difficult to forecast both the context in which the framework might operate and the types of challenges it might face. (2) Commitments made now may be sorely regretted later, especially as they might apply to promises of force levels, funding, host-nation support, base structure, etc. (3) There is no evidence or previous experience with the regional countries that suggests that a formal structure is the best approach; most observers think there is more reason to favor an unstructured arrangement, an informal framework. My point here is that no one should expect that Washington, or others, will try now to present a concrete proposal about a new framework for regional security. The time is not yet right.

The existing framework, it should be remembered, did not originate as a formal structure and has not over the years taken on an institutionalized form, even as it matured. Instead, it has gradually evolved into a complex matrix of treaty commitments, joint communiquйs and declarations, explicit and implicit understandings, and guidelines; there are even important elements that derive from national constitutions and domestic laws, among other things. Yet this accumulation of diverse components has been, for the most part, quite successful for several decades in preventing the outbreak of hostilities, deterring aggression, and discouraging military adventures - despite profound regional divisions and differences. Moreover, the security situation created has promoted, or at least permitted, remarkable stability, political development, and economic 
progress (notwithstanding the recent financial crisis).

There is food for thought here in considering how to proceed. These results seem to argue, at a minimum, for the exercise of caution in discarding components of the existing structure. The analogy of children playing with blocks comes to mind. There is, in contemplating the reconstruction necessary to shape a future security framework, much to say here for carefully rearranging the blocks rather than knocking down the whole stack and starting over. Nevertheless, considerable thought needs to be given to at least the preferred general shape of the new structure it seems inevitable, (especially after there is some form of resolution on the Korean Peninsula that the existing framework will take on a new shape possibly more fundamentally changed than at the end of the Cold War. That implies opportunity but also possible peril.

One viewpoint concerning a new architecture, as described previously, is that the U.S. alliances with Japan and the ROK should, for the foreseeable future, remain important, solid elements of any framework. Adjustments to the U.S. military presence in Asia may well be warranted, even demanded by both the American public and Congress and host governments, but the alliances would remain essentially intact. Advocates of this viewpoint emphasize the benefits that have come about for all nations of the region from the stability that has been a product of the American presence and its important alliances. Even countries like North Korea that complain the loudest about the U.S. presence have, on occasion, acknowledged that the U.S. presence has been a beneficial, stabilizing factor. China has on many occasions expressed the view that it is more content about Japan as a consequence of the U.S.-Japan arrangements and far from unhappy about the effects of U.S. presence in South Korea. The character of the U.S. presence and the degree of cooperation and support provided by the ROK and Japan have been carefully considered and calibrated over the decades. The recently revised Defense Guidelines for the U.S.-Japan security alliance are a notable example of the most deliberate and carefully conceived adjustment, taking into account domestic considerations as well as the changing security situation. Although all will not agree, the new guidelines are considered by those who designed them to provide greater clarity concerning commitments and obligations, to prevent surprises (to all concerned, including Beijing) during a time of crisis, and to avoid the. Perception that such cooperation is provocative or threatening to others.

My own personal, and admittedly not wholly objective, view is that it would be foolhardy to take precipitous action in altering the U.S. alliances or the 
American presence in East Asia. It is simply too early to forecast what the security environment will be in the aftermath of changes in Korea. New threats to peace and stability may take many forms, some we understand now and some that we may have trouble imagining at present. Furthermore, it is imprudent unnecessarily to take actions that may become essentially irrevocable. For example, because of various American domestic factors as well as regional ones, the withdrawal of U.S. forces from Asia mad be an action that would be almost impossible to reverse once taken. No responsible government wants to see a dangerous power vacuum in the region or a rush to fill such a void, should it occur. Even for the most adamant America bashers, the U.S. is the "devil they know."

It is evident, of course, that Beijing's concept of a future security architecture would not include as prominent features U.S. security alliances, and may well favor their dissolution. Although Beijing has never been in a hurry for the American alliances to end, there is the long-term view held by many in China that Asian security problems should eventually be the exclusive domain of Asian countries - that the oft-stated Chinese preference for no troops on foreign soil is more than a self-serving slogan.

China wants its role as an emerging major regional nation fully recognized. Beijing rails against what it calls American attempts at hegemony, and Washington does not want China to assume any such dominant posture. Nonetheless, fear of hegemony, by any party, must not obscure the fact that China is the largest and most populous country of the region and that it has legitimate aspirations for a constructive role in the security affairs of the region. It seems to me that this conviction on the part of Beijing is an underlying element of the strategic partnership concept that China has announced with Russia and advocated as the way of the future. To explain this way, China does not want to see itself as the apparent, if unnamed, adversary of alliances in the region and understandably wants instead to be a part of the architecture.

I have highlighted the importance to Washington of its traditional bilateral alliances as central features of any new security architecture and tried to capture some of Beijing's concerns. New importance, however, should be attached to what has been called a "growing pattern of security pluralism." This pattern, of course, includes multilateral security dialogues, the most prominent of which is the ARF. It is not, in my opinion, inappropriate to mention the ARF in a Northeast Asian context, not because that body is attempting to intrude outside its region (Southeast Asia) but rather because the ARF is providing a venue where 
nations of Northeast Asia meet and discuss security matters - such issues as confidence building and transparency, which might seldom if ever arise naturally and without direct confrontation in other meetings. This demonstrates the applicability of such methods to Northeast Asia.

As the U.S. Department of Defense's 1998 East Asia Strategy Report states: "Multilateralism in all its forms will become an important element of U.S. engagement in the region in coming years." Only a short time back, neither Washington nor Beijing thought well of the concept of multilateralism. Americans thought multilateralism threatened its important bilateral arrangements. The Chinese considered multilateralism as a way for others to gang up on China. So, the American vision of security in Northeast Asia is a network of overlapping and interlocking institutions and relationships that "establish a diverse and flexible' framework for promoting common security in the Asia-Pacific region into the next century," to quote the U.S. Department of Defense's East Asia Security Report (EASR) once more. Beijing might ascribe too much of this multilateral thinking as well. I am exceedingly encouraged by this vision.

Let me now introduce a radical concept, at least in the eyes of some Asians. As I spoke in Seoul two years ago when the Symposium on Northeast Asian Security (SNEAS) was held at KIDA, more than one eyebrow was raised as a consequence of my suggesting that Beijing must be part of the process, "that it will be far better for Beijing to be a part of the framework for security in Northeast Asia than to feel itself an outsider, or worse, an adversary," as I said then. Far fewer eyebrows are raised these days, not because my insight was so brilliant or revolutionary but rather because so many people who are working hard on the problems of security in Northeast Asia has arrived at the same conclusion. I remain convinced of the validity of this assertion even in the light of the downturn in U.S.-China relations following the tragic mistaken bombing of the Chinese embassy in Belgrade and the demonstrations and destruction of American diplomatic buildings in China. There can and must be room for China in a framework based on security pluralism.

Thus we see that there are two largely contradictory (possibly even diametrically opposed) views of the role of bilateral alliances in the regional security architecture. However, the concept of security pluralism seems to hold the promise of finding a middle ground. Consequently, the real issue at hand, it seems to me, is not to choose one view over the other but rather to find a way to accommodate both views of the role of alliances and to make the most of the emergence of pluralism, a concept in which, incidentally but importantly, Mongolia can find its proper place. 
As suggested previously, it may be that China could find the concept ofbilateral alliances far less egregious if it did not inevitably have to conclude that the alliances target China. Among the first steps along such a path might be fostering the realization that alliances need not have identified adversaries, target countries, as their reason for existence and that no country need be a target of these alliances unless its conduct makes it so. These realizations, despite their simplicity, cannot be brought about with a sweep of the hand and a few happy words, but actions consistent with these concepts by all the capitals involved can foster credibility and make the ideas easier to accept as part of the new security framework.

This concept can be worded another way: No country which desires to be an integral part of the security architecture can be seen as a looming threat to regional security and stability. This will require a good measure of introspection by all the countries that aspire to be constructive components of a new framework.

In this regard, there are several important questions that we should ask of ourselves. How does Washington explain what it sees as its role in a new or modified framework in such a way that even the detractors, the America bashers, know that the U.S does not aspire to be a regional hegemony? Does Washington need to make it even clearer that it sees U.S. interests best served by stable, open, and prosperous nations in East Asia, not only clearly progressive countries like Mongolia but also unquestionably including an undemocratic China? How does Japan more effectively convince its neighbors that its goal is not a militaristic future? Does China have to do more to earn a place in the architecture and to demonstrate that it will not threaten Mongolia militarily or economically, for example? How might China cut the Gordian knot of the Taiwan issue? How does it deal with the firm convictions by others that Taiwan is not wholly an internal issue and that a peaceful resolution of the problem is the only way that makes sense? What are the ingredients that will make a unified Korea a welcome part of the framework? What are the appropriate places for Mongolia and Russia in the new architecture? To the extent that we are unwilling to address these questions with candor and a desire to understand the views of other capitals, we make any future security framework less strong and less stable.

The future will bring new and different security architecture for the region. This prospect has great promise and should be approached with optimism and enthusiasm. However, it is also a sobering task, so I conclude with a list of seven reminders of the various formulas that would likely result in failure to construct 
a stable and effective new security framework for Northeast Asia. We must avoid these formulas for failure: (1) seeking formality and rigidity in composition and organizational structure - the fallacy of attempting to form something like NATO in Northeast Asia, (2) failing to appreciate China's appropriate place in the architecture and ignoring Beijing's views in shaping the concept, (3) prejudging the outcome on the Korean peninsula; i.e., assuming we can forecast the precise form of the resolution of the Korean problem, (4) waiting until after change on the Korean Peninsula to lay the groundwork - to consider seriously what will foster a stable and enduring framework, (5) acting hastily in reconsidering and readjusting American alliances and forward presence in Asia, (6) failing to include all the countries of the region and to find a way to blend the bilateral, the multilateral, and the miniature mechanisms that all have roles to play, and (7) assuming we can understand and foresee the nature of future security contingencies that will threaten the region.

This is admittedly a daunting task, especially when one recognizes that no one is in charge and that no one can be in charge. This has to be, it seems to me, an international collegial effort. That heightens the challenge, but it also, one can hope, heightens the prospects that the new framework will sufficiently and appropriately reflect the composition and character of region so that it will not be subjected to assaults from those who feel they have been shunned or ignored, whether those be lesser or greater powers. There is good reason to fear that a new framework will be doomed to instability if it is constantly being shaken by outsiders who are either trying to get in or trying to dismantle the structure. This is not to suggest that making the new security framework inclusive of all who should be part of the architecture will be an easy task. However, despite the extent of the difficulty, it will be easier to resolve these problems now than to try later to cope with the inevitable assaults on the framework by those who have been left out in the cold. Having said all this, the most challenging aspect of developing a new architecture, largely and unavoidably derived from traditional security perspectives may be to apply this architecture to a new world of non-traditional security concerns, for example the peacekeeping operations that Mongolia's forces may become well suited to conduct. But that, of course, is the subject of another speech, one that I would welcome the opportunity to deliver on another visit to your impressive and beautiful country. 